Diabetologia 8, 136-140 (1972)

(C) by Springer-Verlag 1972

\title{
Electrophoretic Characterization of Circulating Human Proinsulin and Insulin*
}

\author{
R.A. Gutman, N.R. Lazarus, and L. Reoant \\ Veterans Administration Hospital, Diabetes Research Laboratory and Georgetown University, School of Medicine, \\ Washington, D.C., U.S.A.
}

Received: August 30, 1971, accepted: Dezember 21, 1971

\begin{abstract}
Summary. The serum proinsulin and insulin components of normal weight subjects treated with tolbutamide, or glucose and tolbutamide, were shown to be homogeneous on both Sephadex filtration and polyacrylamide gel electrophoresis. Serum of obese subjects treated with glucose and tolbutamide contained, in addition to proinsulin and insulin, two intermediate species when electrophoresed on polyacrylamide gel, i.e., desdipeptide proinsulin and diarginyl insulin. It is suggested that, 1. the conversion of proinsulin to insulin proceeds via these intermediates under physiological conditions, and 2. intermediates may appear in the circulation with excessive elevations of plasma immunoreactive insulin materials.
\end{abstract}

Caractérisation par électrophorèse de la proinsultine et de l'insuline humaines circulantes

Résumé. Les composés de la proinsuline et de l'insuline du sérum chez des sujets de poids normal traités à la tolbutamide ou au glucose + tolbutamide se sont montrés homogènes dans la filtration sur Sephadex et dans l'électrophorèse sur gel de polyacrylamide. Le sérum des sujets obèses traités au glucose + tolbutamide contenait, en plus de la proinsuline et de l'insuline, deux substances intermédiaires lorsque l'électrophorèse était faite sur gel de polyacrylamide, par exemple, desdipeptide proinsuline et diarginyle insuline. On suppose que la conversion de la proinsuline en insuline se fait par ces intermédiaires dans los conditions physiologiques.

Elektrophoretische Charalterisierung von zirkulierendem menschlichem Proinsulin und Insulin

Zusammenfassung. Das Proinsulin des Serums und Insulinkomponenten von normalgewichtigen Personen, die entweder mit Tolbutamid oder mit Glucose und Tolbutamid behandelt wurden, zeigten sowohl auf Sephadex als auch in der Polyakrylamidelektrophorese einen gleichen Effekt. Serum von Übergewichtigen, welche mit Glucose und Tolbutamid behandelt wurden, enthielt zusätzlich zum Proinsulin und Insulin zwei Zwischensubstanzen bei der Polyakrylamidelektrophorese: Desdipeptid-Proinsulin und Diarginyl-Insulin. Daraus wird abgeleitet, daß die Umwandlung von Proinsulin in Insulin unter physiologischen Bedingungen über diese Zwischensubstanzen verläuft.

Key words: Proinsulin, insulin, serum IRI (immunoreactive insulin), serum IRI intermediates, IRI species, obesity.

\section{Introduction}

In the serum of human subjects, two insulin immunoreactive (IRI) peaks have been identified by the use of gel filtration $[1,2,3]$. One fraction behaves as proinsulin, the other one as insulin. Because of the poor resolving power of gel filtration, it is as yet undetermined whether these two peaks are heterogenous or homogeneous. The possibility of heterogeneity arises from the work of Steiner et al. [4] on proinsulin prepared from beef pancreas. These workers showed that intermediate species can be present in the gel filtered proinsulin fraction. Further, Chance has isolated, purified, and identified intermediates of proinsulin from porcine pancreas as well as from crude insulin [5]. In this report, circulating IRI material from several, selectively treated, subjects has been characterized by polyacrylamide electrophoresis and gel filtration.

\section{Materials and Methods}

Plasma samples from 4 normal weight and 3 obese subjects (greater than $30 \%$ of ideal body weight) were 11578 obtained $15 \mathrm{~min}$ after the intravenous administration of tolbutamide. Three obese and one normal weight subject were "hyperstimulated" by the administration of $300 \mathrm{~g}$ of glucose $(150 \mathrm{~g} \mathrm{IV}+150 \mathrm{~g}$ per os) prior to the tolbutamide injection. Plasma IRI determinations were carried out according to the Morgan and Lazarow method [6], using the conditions previously described [7]. Components of the plasma IRI were characterized by a) gel filtration on Sephadex G-50. Superfine, zquilibrated in $5 \%$ bovine albumin in veronal buffer pH 8.6 [7], and b) polyacrylamide gel electrophoresis carried out according to the method of Lazarus et al. [8]. Samples for gel electrophoresis were prepared by acid alcohol extraction [9] and, where necessary, fractions were concentrated by use of Amicon ultrafilters. High concentrations of IRI in samples applied to gels did not effect the migration patterns. Plasma acid alcohol extracts, to which up to $0.5 \mu \mathrm{g}$ of either purified porcine proinsulin or insulin had been added, showed the same discrete peaks (no spread of IRI) compared with samples containing only 10 to $50 \mathrm{~m} \mu \mathrm{g}$ of the same materials.

Porcine proinsulin was purchased from Elanco Products Co., a subsidiary of Eli Lilly Co. Human insulin (single component) and porcine diarginyl insulin were a gift of Dr. Ronald Chance of the Eli Lilly Co. 
and were utilized as standards in the columns and gels. All other chemicals were purchased from Fisher Scientific Co.

\section{Results}

Patterns of circulating IRI in normal weight subjects. The electrophoretic behaviour of human proinsulin was established as follows: A plasma sample obtained $15 \mathrm{~min}$ after hyperstimulation of a normal weight subject $(720 \mu \mathrm{U}$ IRI $/ \mathrm{ml})$ was filtered on Sephadex and the proinsulin and insulin peaks separately extracted with acid alcohol, concentrated and subjected to gel electrophoresis. The insulin peak migrated as a homo-

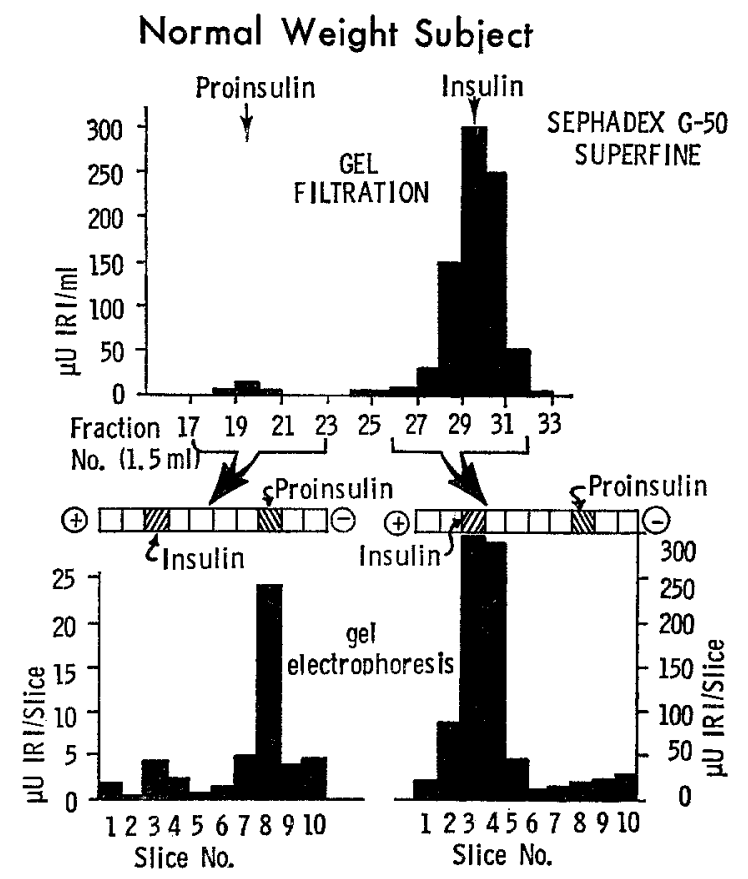

Fig. 1. Serum sample was obtained after glucose and tolbutamide stimulation (for details see text). After gel filtration $(1 \times 40 \mathrm{~cm}$ column) of $2 \mathrm{ml}$ of serum $(720 \mu \mathrm{U}$ IRI $/ \mathrm{ml}$ ) proinsulin and insulin peaks were extracted with acid alcohol, ultrafiltered and then subjected to gel electrophoresis. Single IRI peaks were observed at slices 8 and $3-4$ respectively. Recovery from gel filtration was $83 \%$ and from gel electrophoresis was $65 \%$

geneous species at slice 3. Proinsulin migrated as a single band at slice 8 (Fig. 1). IRI at slices 3 and 4 probably represented contamination with insulin.

Plasma obtained from 3 normal weight subjects 15 min after stimulation with tolbutamide (100$150 \mu \mathrm{U}$ IRI $/ \mathrm{ml}$ ) showed less than $5 \%$ of the total IRI eluting as proinsulin, when filtered through Sephadex G-50. Over 95\% eluted as insulin. After gel electrophoresis of these plasma acid alcohol extracts, almost all the IRI material migrated as a single band in the position of the insulin standard (Fig. 2). In 1 of the 3 subjects a small band in position 6 was apparent, while proinsulin was also present.
Patterns of circulating IRI in obese subjects. Obese subjects given glucose and tolbutamide responded with a significantly higher insulin output. Plasma IRI levels ranged from 3-5000 $\mu \mathrm{U} / \mathrm{ml}$. However, gel filtration of these samples showed essentially the same relative concentrations of proinsulin and insulin as those from the lean subjects, i.e., 5 and $95 \%$ respectively. When

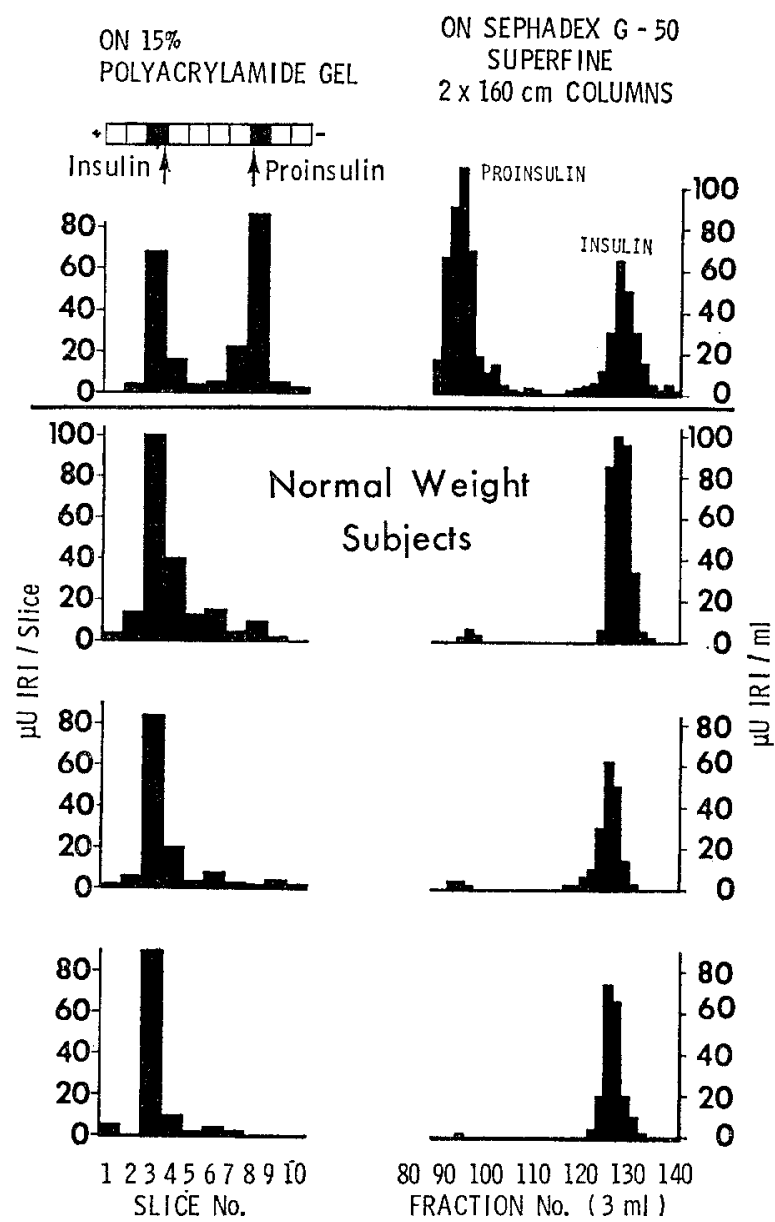

Fig. 2. Serum samples were obtained after tolbutamide injection. $2 \mathrm{ml}$ of serum were used for gel filtration. Acid alcohol extracts of $2 \mathrm{ml}$ of serum were used for polyacrylamide electrophoresis. Major IRI peaks electrophoresing as insulin were found in all 3 subjects. Additional very minor IRI components may be noted

acid alcohol extracts of $1 \mathrm{ml}$ of plasma obtained from obese subjects were electrophoresed on polyacrylamide, a significant amount of IRI material migrated in an intermediate position between the proinsulin and insulin (Fig. 3). To determine the origin of the intermediate species, the proinsulin and insulin fractions obtained after gel filtration were separately extracted, concentrated and subjected to gel electrophoresis. Both the proinsulin and insulin peaks contained small amounts of one intermediate species each (Fig. 4). It should be noted that the proinsulin species is not contaminated with insulin, nor the insulin with proinsulin. 


\section{Discussion}

Normal weight subjects after stimulation with either tolbutamide or glucose plus tolbutamide had no intermediate forms in the circulation detectable either by gel filtration or polyacrylamide gel electrophoresis of serum. Thus, the influence of intermediate species

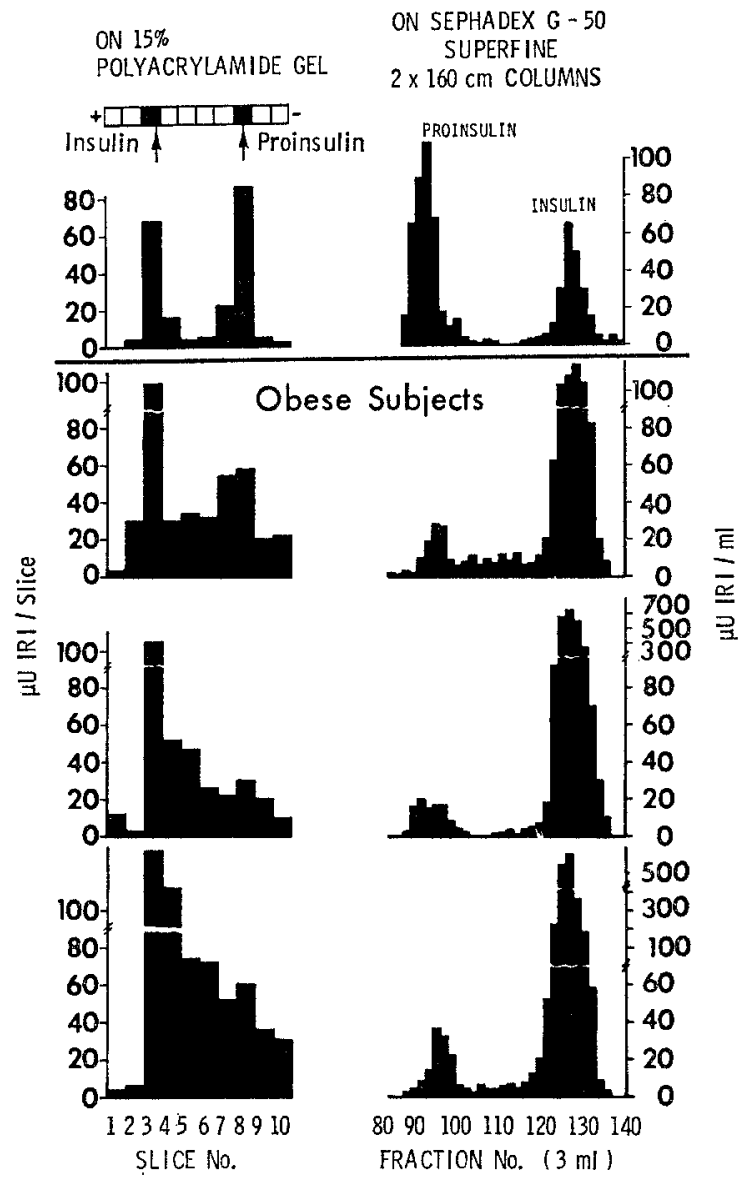

Fig. 3. Serum samples were obtained after glucose and tolbutamide stimulation. $2 \mathrm{ml}$ of serum $(3-5000 \mu \mathrm{U} / \mathrm{ml})$ were used for gel filtration. Acid alcohol extract of $1 \mathrm{ml}$ of serum was applied to gel electrophoresis. IRI material migrating in an intermediate position between proinsulin and insulin was found in all 3 obese subjects

on the plasma IRI measurements in normal subjects under standard conditions of stimulation can be discounted. Obese subjects, after stimulation with glucose plus tolbutamide also showed homogeneous proinsulin and insulin peaks on gel filtration. However, gel electrophoresis of the proinsulin and insulin peaks showed them to be heterogeneous, in that they contained at least one intermediate species each. This suggests that more elaborate methods than gel filtration are needed in order to assess the nature of the IRI material measured by a standard insulin immunoassay.

When an obese subject was stimulated with tolbut- amide alone, IRI levels were found to be only $1 / 10$ of that observed in hyperstimulated obese subjects. In contrast to the hyperstimulated subjects, no intermediate IRI species were found after gel electro-

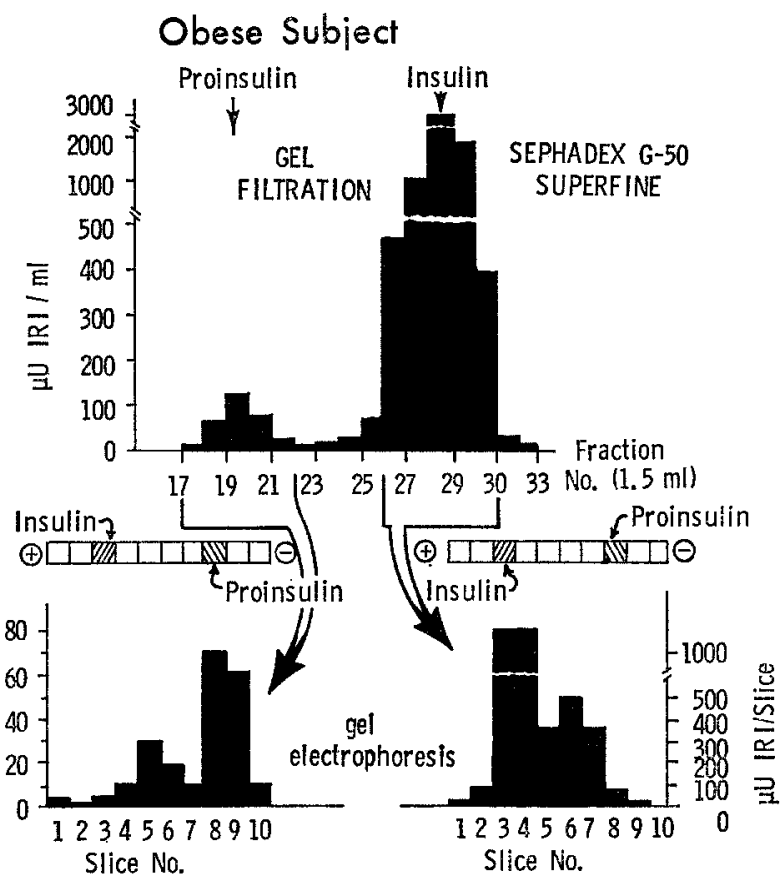

Fig. 4. Serum sample was obtained after glucose and tolbutamide stimulation (for details see text). $2 \mathrm{ml}$ of serum $(4100 \mu \mathrm{U} \mathrm{TRI} / \mathrm{ml})$ were treated as in Fig. 1. The proinsulin and insulin peaks obtained after gel filtration each contained an intermediate species. Notice the faster electrical mobility of the proinsulin intermediate as compared to the insulin intermediate (slices 5 and 6 respectively)

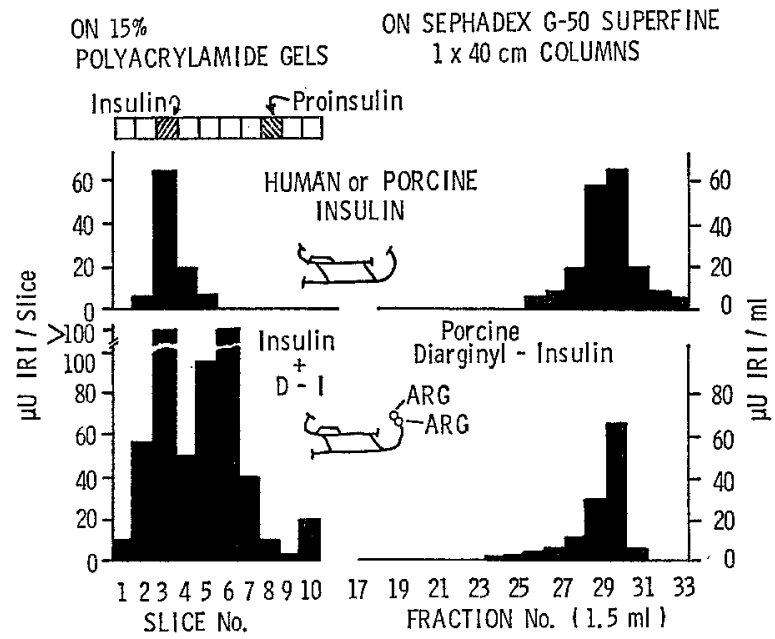

Fig. 5. Electrophoresis on all samples were carried out on acid alcohol extracts of $1 \mathrm{ml}$ of fasting human serum (containing less than $10 \mu \mathrm{U}$ IRI) to which insulin and diarginyl insulin had been added. Diarginyl insulin elutes in the same position as insulin after Sephadex filtration. On polyacrylamide electrophoresis, insulin (slice 3) and diarginyl insulin (D-I) (slice 6) are clearly separated 
phoresis. (Data not shown.) This suggests that heterogeneity may be a phenomenon accompanying excessive elevation of plasma IRI. However, the presence of small amounts of intermediates, undetectable by our methods, under standard conditions of stimulation can not be ruled out.
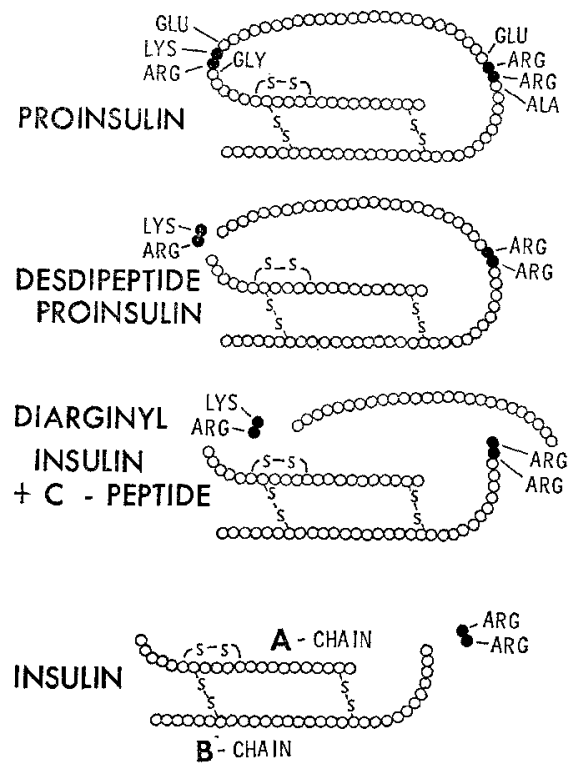

Fig. 6. The proinsulin structure shown at the top of the graph represents porcine proinsulin. Connecting peptide (C peptide) connects the amino terminal end of A-chain with the carboxyl terminal end of B-chain of insulin. The main differences between porcine and human proinsulin are, a) the number of amino acids in the C-peptide (human proinsulin contains 5 extra amino acids), and $b$ ) alanine at the carboxyl end of the B-chain is replaced in human proinsulin by threonine. The basic dipeptides LysArg and Arg-Arg where the proteolytic process takes place is the same in porcine, bovine and human proinsulins

The electrophoretic behaviour of the intermediate species in the insulin peak was found to be identical with that of porcine diarginyl insulin (Fig. 5). Because we have found porcine and human insulin to behave identically on gel electrophoresis, the corresponding diarginyl derivatives should behave identically. Monoarginyl insulin migrates in a position intermediate between insulin and diarginyl insulin on gel electrophoresis (slices $4-5$ ). Thus, we identify the intermediate component present in the insulin peak as diarginyl insulin. However, the possibility remains that the insulin intermediate could be the Lys-Arg insulin derivative (consisting of the Lys-Arg dipeptide attached to the amino-terminal end of the $A$ chain), which we can assume will behave identically with diarginyl insulin on both gel filtration and gel electrophoresis. The following points are in favour of this intermediate being diarginyl insulin: a) Arg-Gly (see Fig. 6) is the first peptide bond to be cleaved upon trypsin treatment of porcine proinsulin [5]; b) Trypsin treatment of bovine [11] or porcine proinsulin [5] yields diarginyl insulin at an early stage of digestion; c) Diarginyl-insulin derivative has been isolated from crude porcine insulin [5] while, as yet, the isolation of a Lys-Arg derivative from either pancreas or crude insulin has not been reported.

The proinsulin intermediate migrated faster on gel electrophoresis than proinsulin. Further, on a $2 \times$ $160 \mathrm{~cm}$ Sephadex column, this intermediate eluted as intact proinsulin. The column is able to discriminate between intact proinsulin and desnonapeptide proinsulin, a change in mol. wt. of approximately $13 \%$. Thus, the molecule under consideration must differ from intact proinsulin by less than 9-10 residues. Kemmler and Steiner [10] have shown that by the combined use of trypsin and carboxypeptidase B, desdipeptide proinsulin (missing basic residues LysArg) is formed. In addition, Schmidt and Areus [12] have isolated desdipeptide proinsulin (missing dipeptide Lys-Arg, see Fig. 6) from crude bovine insulin. The points mentioned above suggest that the proinsulin intermediate is desdipeptide proinsulin (missing the basic dipeptide Lys-Arg). Further, the fact that $C$ peptide has been found in equimolar concentrations with insulin in bovine and porcine pancreas [11], human pancreas [13] and human serum [14] suggests that no intermediate forms beyond desdipeptide proinsulin and diarginyl insulin are formed.

Although the above mentioned observations support the identification of the intermediates as desdipeptide proinsulin and diarginylinsulin, other possibilities such as desarginine proinsulin can not be ruled out.

If the intermediates present in obese serum are desdipeptide proinsulin and diarginyl insulin, the above suggests that in human subjects the formation of insulin from proinsulin occurs by the following reaction sequence: cleavage of bonds Arg-Gly and Glu-Lys releasing the desdipeptide proinsulin. This would be followed by cleavage of bond Arg-Glu releasing both the $\mathrm{C}$ peptide and diarginyl insulin. The final step is cleavage of bond (Thr-Arg) with release of insulin (Fig. 6). This is the first report of electrophoretic heterogeneity in circulating IRI material. It remains to be established why intermediate species appear in the circulation of obese subjects after being hyperstimulated with glucose plus tolbutamide and the role of these intermediates in the pathophysiology of obesity.

\section{References}

1. Roth, J., Gorden, P., Pastan, I.: "Big Insulin": a component of plasma insulin detected by immunoassay. Proc. nat. Acad. Sci. 61, 138-145 (1968).

2. Melani, F., Rubenstein, A.H., Steiner, D.F.: Human proinsulin. J. clin. Invest. 49, 497-507 (1970).

3. Goldsmith, S.T., Yalow, R.S., Berson, S.A.: Significance of human plasma insulin sephadex fractions. Diabetes 18, 834-839 (1969).

4. Steiner, D.F. Hallund, O., Rubenstein, A., Cho, S., Bayliss, C.: Isolation and propertios of proinsulin, 
intermediate forms and other minor components from crystalline bovine insulin. Diabetes 17, 725-736 (1968).

5. Chance, R.E.: Proinsulin and the biosynthesis of insulin. Rec. Progr. Horm. Res. 25, 272-282 (1969).

6. Morgan, C.R., Lazarow, A.: Immunoassay of insulin: two antibody system: plasma insulin levels of normal, subdiabetic and diabetic rats. Diabetes 12, 115-126 (1963).

7. Gutman, R.A., Lazarus, N.R., Penhos, J.C., Recant, L.: Circulating proinsulin-like material in patients with functioning insulinoma. New Engl. J. Med. 284, $1003-1008$ (1971)

8. Lazarus, N.R., Gutman, R.A., Recant, L.: A method for electrophoretic characterization on polyacrylamide gel of circulating insulin immunoreactive substances. Anal. Biochem. 40, 241-246 (1971).

9. Davoren, P.R.; The isolation of insulin from a single cat pancreas. Biochim biophys. Acta. 63, 150-153 (1962).

10. Kemmler, W., Peterson, J.B., Nehrlich, S., Steiner, D.F.: On the transformation of proinsulin to insulin in vitro and in vivo. Diabetes 20, Suppl. I, 332 (1971).
11. Steiner, D.F., Cho, S., Oyer, P.F., Terris, S., Peterson, J.D., Rubenstein, A.H.: Isolation and characterization of proinsulin C-peptide from bovine pancreas. J. biol. Chem. 246, 1365-1374 (1971).

12. Schmidt, V.D.D., Arens, A.: Proinsulin vom Rind Isolierung, Eigenschaften und seine Aktivierung durch Trypsin. Hoppe-Seyler Z. Physiol. Chem. 349, 1157 1168 (1968).

13. Oyer, P.E., Cho, S., Peterson, J.D. Steiner, D.F.: Studies on human proinsulin. J. biol. Chem. 246, $1375-1386$ (1971).

14. Melani, F., Rubenstein, A.H., Oyer, P.E., Steiner, D.F.: Identification of proinsulin and C-peptide in human serum. Proc. nat. Acad. Sci. 67, 148-155 (1970).

Dr. Norman R. Lazarus, Veterans Administration Hospital, Diabetes Research Laboratories, 50 Irving St., N.W.,

Washington, D.C. 20422, U.S.A. 